\title{
Clorofilina inibe a multiplicação de poliovírus em cultura de células HEp-2
}

\section{Chlorophyllin inhibits the multiplication of poliovirus in HEp-2 cell cultures}

\author{
Lígia Carla Faccin'; José Augusto Ramos Medeiros; \\ Mario Sergio Mantovani ${ }^{3}$; Carlos Nozawa ${ }^{4}$; Rosa Elisa Carvalho Linhares ${ }^{4}$
}

\section{Resumo}

\begin{abstract}
A clorofilina (CHLN), derivado sintético da clorofila com atividade antimutagênica, foi analisada quanto a sua atividade antiviral para o poliovírus em culturas de células HEp-2. A droga foi avaliada quanto às atividades virucida, profilática e terapêutica na multiplicação do poliovirus em culturas de células $\mathrm{HEp}-2$, nas concentrações de 0,5 e $2,5 \mu \mathrm{g} / \mathrm{mL}$. A inibição do título viral e a reação de imunofluorescência foram utilizadas para avaliação. A CHLN inibiu a multiplicação do poliovírus nos três protocolos de tratamento, porém foi mais efetiva no tratamento virucida inibindo em $95,7 \%$ a multiplicação viral na concentração de $2,5 \mu \mathrm{g} / \mathrm{mL}$. A CHLN reduziu o número de células infectadas com fluorescência específica, nos tratamentos virucida, e terapêutico, $8 \mathrm{~h}$ e $10 \mathrm{~h}$ pós-infecção, nas duas concentrações $(0,5$ e $2,5 \mu \mathrm{g} / \mathrm{mL})$. Sugere-se que a CHLN tem uma ação direta na partícula viral ou provavelmente age nos estágios iniciais da multiplicação do poliovirus.
\end{abstract}

Palavras-chave: Clorofilina. Poliovírus. Antiviral. Cultura de células.

\begin{abstract}
Chlorophyllin (CHLN), a semisynthetic derivative of chlorophyll with antimutagenic properties, was assayed for its antiviral effect on the replication of poliovirus in cell culture. The drug was tested for the virucide, prophylactic and therapeutic activities on the replication of the poliovirus in HEp-2 cells cultures, at concentrations of 0.5 and $2.5 \mu \mathrm{g} / \mathrm{mL}$. Virus titration and an indirect immunofluorescence test were used for the evaluation. The CHLN inhibited poliovirus replication in all treatment protocols; however, it was more effective on virucide treatment, with a $95.7 \%$ reduction in viral multiplication at concentration of $2.5 \mu \mathrm{g} / \mathrm{mL}$. CHLN reduced the number of specifically fluorescent infected cells in both virucide and therapeutic treatments, $8 \mathrm{~h}$ and $10 \mathrm{~h}$ post-infection, at both concentrations $(0.5$ and $2.5 \mu \mathrm{g} /$ $\mathrm{mL}$ ). It is suggested that CHLN either has a direct action on the virus particles or acts on the initial stage of the poliovirus replication.
\end{abstract}

Keywords: Chlorophyllin. Poliovirus. Antiviral. Cell culture.

1 Professor Assistente do Departamento de Ciências Patológicas da Universidade Estadual de Londrina. E-mail: 1galhardi@ sercomtel.com.br.

2 Biomédico pela Universidade Estadual de Londrina.

3 Professor Adjunto do Departamento de Biologia Geral da Universidade Estadual de Londrina.

${ }^{4}$ Professores Adjuntos do Departamento de Microbiologia da Universidade Estadual de Londrina.

Semina: Ciências Biológicas e da Saúde, Londrina, v. 29, n. 1, p. 75-82, jan./jun. 2008 


\section{Introdução}

O tratamento das infecções virais continua a ser um desafio devido, sobretudo pela dificuldade de se desenvolver drogas antivirais capazes de inibir a multiplicação viral sem afetar a célula hospedeira. Várias drogas sintéticas foram desenvolvidas e testadas bem como algumas substâncias naturais para o tratamento de uma variedade de infecções virais (JONES, 1998). Em relação as substâncias naturais, Lagrota et al. (1983) estudaram o efeito do lapachol, extraído de planta, principalmente, do gênero Tecoma (família Bigoniaceae), sobre vários vírus de RNA e DNA em cultura de células e em ovos embrionados. O lapachol mostrou eficácia somente sobre os vírus RNA, envelopados ou não. Uma fração polissacarídica extraída de folhas de Cedrela tubiflora Bert (família Meliaceae) inibiu a multiplicação dos vírus Herpes simplex e vírus da estomatite vesicular, porém não afetou a multiplicação do vírus pólio (CRAIG; BENENCIA; COULOMBIÉ, 2001). Glatthaar-Saalmüller, Sacher e Esperester (2001) descreveram a atividade antiviral de extrato da semente de Eleutherococcus senticosus contra vários vírus RNA (rinovírus, vírus respiratório sincicial e influenza $\mathrm{A}$ ), porém a droga não apresentou nenhum efeito sobre os vírus DNA (HSV-1 e adenovírus 5) testados.

Semple et al. (2001) testaram a atividade do ácido crisofânico, extraído de uma planta medicinal da Austrália, na multiplicação do poliovírus em cultura de células e verificaram a inibição nas primeiras etapas da replicação viral.

A clorofilina (CHLN), derivado sintético da clorofila, solúvel em água, tem sido analisada, quanto às suas propriedades antimutagênicas (SARKAR; SHARMA; TALUKDER, 1994). Essa substância tem sido utilizada no tratamento da cicatrização e no controle de odores corporais, urinários e fecais em pacientes geriátricos. Tem sido estudada também como protetora contra agentes genotóxicos, como Trp-P-2 (NEGISHI et al., 1990), brometo de etídio e óxido de estireno (BRONZETTI; GALLI; DELLA
CROCE, 1990), benzo[ $\alpha]$ pireno (ARIMOTO et al., 1995) aflatoxina B1 e nitrosaminas relacionadas ao tabaco (WARNER; NATH; ONG, 1991) entre outros. Breinhold et al (1995) demonstraram que a CHLN protege animais contra tumores induzidos por reagentes químicos. A CHLN é usada também como corante em alimentos (NEGISHI; RAI; HAYATSU, 1997).

A atividade antimutagênica in vitro sobre contaminantes ambientais e a ausência de efeito tóxico significativo em seres humanos e animais (ONG et al., 1986) fazem da CHLN um composto ideal como agente quimiopreventivo. Em experimentos realizados in vivo e in vitro, a CHLN apresentou efeitos antioxidantes e pró-oxidantes dependentes de tempo de administração e da dose administrada (KUMAR; SHANKAR; SAINIS, 2004). De acordo com EGNER et al. (2000, 2001, 2003), a CHLN tem sido usada como agente quimiopreventivo em populações de certos paises da China que possuem alto risco de exposição de Aflatoxina B1 que é hepatocarcinogênico. Yun et al. (2005) relataram que a CHLN não induzia a modulação da função imune in vivo, mas inibia a secreção de IFN- $\gamma$ por células hepáticas in vitro. Em 2007, Sharma, Kumar e Sainis verificaram que a administração de CHLN em ratos imunizados com hemácias de ovelha aumentava tanto a imunidade humoral quanto a imunidade mediada por célula.

Devido à inexistência de dados relativos à interação da CHLN com os vírus, este trabalho tem como objetivo avaliar o efeito da CHLN na multiplicação do poliovírus.

\section{Material e métodos}

- Célula: Cultura de células HEp-2 (carcinoma de laringe humana, ATCC CCL-23) cultivadas em meio Dulbecco modificado (DMEM) (Sigma Chem. Co.) acrescido de $8 \%$ de soro fetal bovino (SFB) (Gibco BRL), $100 \mu \mathrm{g} /$ $\mathrm{mL}$ de estreptomicina (Sigma), $100 \mathrm{UI} /$ 
$\mathrm{mL}$ de penicilina $\mathrm{G}$ (Sigma) e $2,5 \mu \mathrm{g} / \mathrm{mL}$ de anfotericina B (Bristol Meyers-Squibb), foram utilizados nos experimentos.

- Vírus: Poliovírus-1 obtido do "American Type and Culture Collection” (ATCC, VR-58) adaptado em cultura de células HEp-2.

- Clorofilina: A solução estoque de CHLN (Sigma Chem. Co. C6003) foi preparada na concentração de $250 \mu \mathrm{g} / \mathrm{mL}$ em tampão fosfato salina (PBS), pH 7,4 e alíquotas foram mantidas $\mathrm{a}-4^{\circ} \mathrm{C}$ protegidas de luz.

Teste de Citotoxicidade da Clorofilina: Células HEp-2 cultivadas em microplacas de 96 escavações foram mantidas com meio DMEM acrescido de CHLN nas concentrações de $1,0 \mu \mathrm{g} / \mathrm{mL} ; 1,25 \mu \mathrm{g} /$ $\mathrm{mL} ; 2,5 \mu \mathrm{g} / \mathrm{mL} ; 5,0 \mu \mathrm{g} / \mathrm{mL} ; 10 \mu \mathrm{g} / \mathrm{mL}$ e $25 \mu \mathrm{g} /$ $\mathrm{mL}$ (doze escavações por concentração da droga) a $37^{\circ} \mathrm{C}$ em ambiente de $5 \%$ de $\mathrm{CO}_{2}$, por dez dias. As culturas foram observadas diariamente em microscópio invertido para verificação de alterações morfológicas.

\section{Atividade antiviral da Clorofilina na multiplicação do Poliovirus}

Para avaliaçãoda atividade antiviral da clorofilina, foram utilizados três protocolos de tratamento: virucida, profilático e terapêutico. Os testes foram realizados em microplacas de 96 escavações, em uma densidade de $10^{6}$ células $/ \mathrm{mL}$, incubadas à $37^{\circ} \mathrm{C}$, em atmosfera com 5\% de $\mathrm{CO}_{2}$. A CHLN foi testada nas concentrações de 0,5 e $2,5 \mu \mathrm{g} / \mathrm{mL}$. O inóculo do vírus utilizado nos testes foi de $10^{7} \mathrm{TCID}_{50} / \mathrm{mL}$. As células foram observadas diariamente, durante sete dias para verificação do efeito citopático (ECP).

- Atividade Virucida. O poliovírus foi incubado a $37^{\circ} \mathrm{C}$ com CHLN por $1 \mathrm{~h}$, nas concentrações acima citadas. Diluições ao décimo $\left(10^{-1}\right.$ a $10^{-}$ ${ }^{11}$ ) do vírus tratado foram inoculadas em células HEp-2 e incubadas a $37^{\circ} \mathrm{C}$.

- Atividade Profilática. Células HEp-2 foram incubadas com CHLN, nas duas concentrações citadas anteriormente, por duas horas a $37^{\circ} \mathrm{C}$. Após esse período, o meio foi removido e as células foram inoculadas com diluições ao décimo $\left(10^{-1}\right.$ a $\left.10^{-11}\right)$ de poliovírus e incubadas a $37^{\circ} \mathrm{C}$ por sete dias.

- Atividade Terapêutica. Células HEp-2 foram inoculadas com poliovírus (diluições ao décimo $10^{-1}$ a $10^{-11}$ ) na presença das duas concentrações da CHLN e em seguida incubadas a $37^{\circ} \mathrm{C}$.

Em todos os testes, foram realizados os controles de células (células não infectadas e não tratadas) e o controle de vírus (células infectadas na ausência da droga). O título do vírus e a porcentagem de inibição viral foram calculados de acordo com, Reed e Müench (1938) e Nishimura, Toku; Fukuyasu (1977) respectivamente. Os testes foram realizados em triplicata e os resultados expressos como a média dos três experimentos.

\section{Reação de Imunofluorescência Indireta (IFI)}

Culturas de células HEp-2 cultivadas em tubos de Leighton foram inoculadas com poliovírus $\left(10^{7} \mathrm{TCID}_{50} / \mathrm{mL}\right)$ para avaliação das atividades virucida e terapêutica da CHLN. Culturas de células não infectadas tratadas e não tratadas com a droga e culturas de células infectadas e não tratadas foram mantidas como controle. As lamínulas foram coletadas $8 \mathrm{~h}$ e $10 \mathrm{~h}$ pós-infecção e fixadas com acetona gelada $\left(-20^{\circ} \mathrm{C}\right)$ durante $20 \mathrm{~min}$. Foi adicionado um pool de soro humano anti-poliovírus na diluição $1: 20$, seguido de incubação a $37^{\circ} \mathrm{C}$ por 30 min em câmara úmida. As lamínulas foram lavadas três vezes, durante 5 min cada, com PBS, seguido de adição de soro de coelho anti-IgG humana conjugado com isotiocianato de fluoresceína diluído 1:100 (Biomanguinhos), e mantido a $37^{\circ} \mathrm{C}$ durante 30 min em câmara úmida. Após lavagens com PBS por três vezes, as lamínulas foram montadas com glicerina tamponada ( $\mathrm{pH} 7,3)$ e observadas ao microscópio equipado com luz UV (Nikon H-III). Os testes foram realizados em triplicata e foram contadas 100 células por lamínula. As células 
consideradas positivas apresentavam fluorescência citoplasmática específica para o poliovírus. O número de focos fluorescentes corresponde à média da contagem de células positivas nos três testes.

\section{Resultados}

O ensaio de citotoxicidade da CHLN mostrou que, a partir do quinto dia de contato, as células tratadas com $25,0 \mu \mathrm{g} / \mathrm{mL}$ da droga apresentaram alterações morfológicas. Nas concentrações de 5,0 $\mu \mathrm{g} / \mathrm{mL}, 10,0 \mu \mathrm{g} / \mathrm{mL}$ e $25,0 \mu \mathrm{g} / \mathrm{mL} 100 \%$ das células apresentavam efeito tóxico no décimo dia. Células tratadas com $2,5 \mu \mathrm{g} / \mathrm{mL}$ não apresentaram qualquer alteração morfológica.

Demonstram-se no gráfico 1 os efeitos da CHLN nos diversos tratamentos (virucida, profilático e terapêutico), no que se refere à infecciosidade dos polivírus. Foi observado que a CHLN inibiu a multiplicação do vírus nas duas concentrações utilizadas tanto na atividade virucida quanto no teste terapêutico, e a sua maior porcentagem de inibição viral, $95,7 \%$, foi observada no teste virucida, utilizando-se $2,5 \mu \mathrm{g} / \mathrm{mL}$ da droga. Quando utilizada de forma profilática, a CHLN inibiu a multiplicação viral em $10,3 \%$ e $31,7 \%$ nas concentrações de 0,5 $\mu \mathrm{g} / \mathrm{mL}$, e $2,5 \mu \mathrm{g} / \mathrm{mL}$, respectivamente.

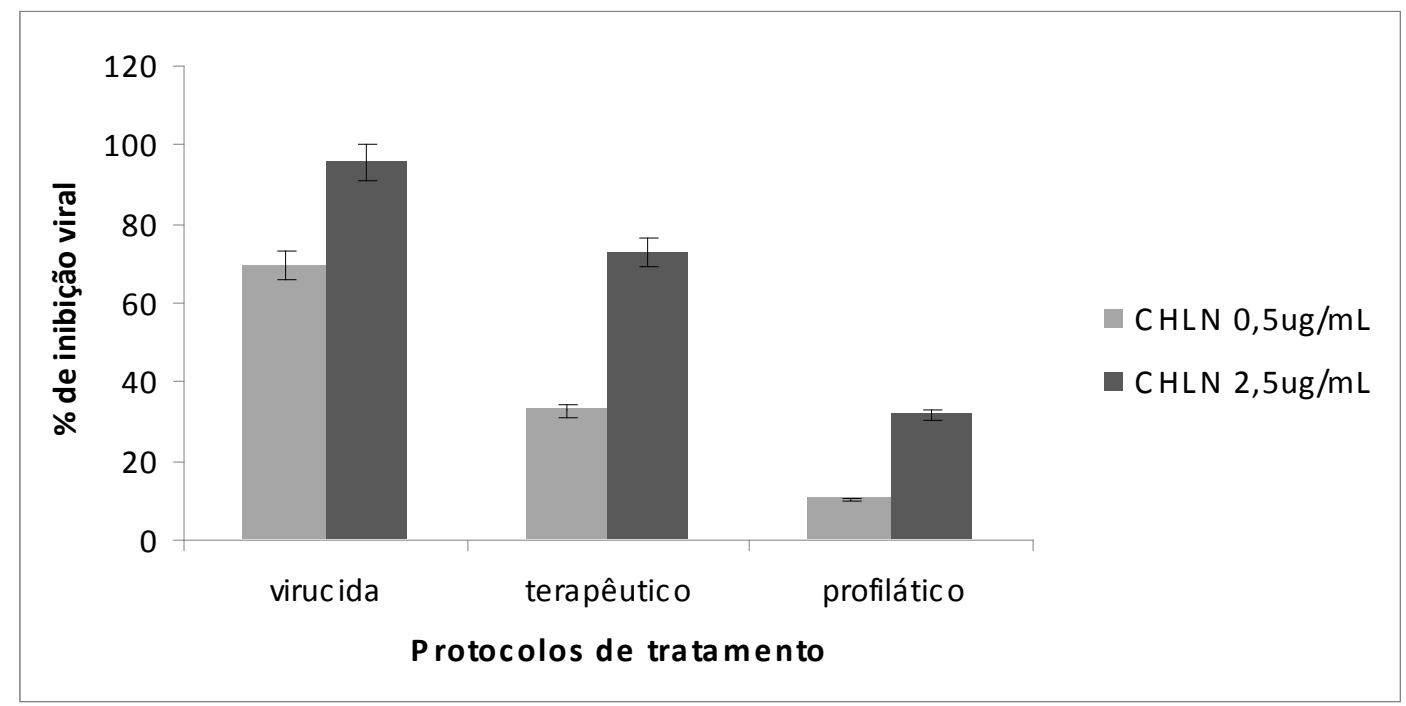

Gráfico 1. Atividade antiviral da clorofilina em células HEp-2 infectadas com poliovírus nos três protocolos de tratamento: virucida, terapêutico e profilático. O cálculo da porcentagem de inibição viral (\%IV) (NISHIMURA; TOKU; FUKUYASU, 1977) foi feito após titulação do vírus pelo método de Reed e Müench (1938).

Os resultados do teste de imunofluorescência indireta estão apresentados na tabela 1. A utilização da droga de forma terapêutica resultou na diminuição no número de células com focos fluorescentes, com relação ao controle de vírus, com cerca de $54 \%, 8 \mathrm{~h}$ pós-infecção e $50 \%, 10 \mathrm{~h}$ pós-infecção, na concentração de $0,5 \mu \mathrm{g} / \mathrm{mL}$. Na concentração de $2,5 \mu \mathrm{g} / \mathrm{mL}$, a diminuição foi de cerca de 58
\% e 55,4\% para os tempos de 8 h pós-infecção e $10 \mathrm{~h}$ pós-infecção, respectivamente. A análise da atividade virucida da CHLN mostrou uma redução de $39,7 \%$, 8 h pós-infecção e $47 \%$, 10h pós-infecção na concentração de $0,5 \mu \mathrm{g} / \mathrm{mL}$. Na concentração de $2,5 \mu \mathrm{g} / \mathrm{mL}$, os resultados foram de $47,0 \%, 8 \mathrm{~h}$ pósinfecção e 49,5\%, 10h pós-infecção. 
Tabela 1. Avaliação das atividades virucida e terapêutica da clorofilina em células HEp-2 infectadas com poliovírus, tratadas nas concentrações de 0,5 e $2,5 \mu \mathrm{g} / \mathrm{mL}$ e monitoradas pelo teste de Imunofluorescência indireta, $8 \mathrm{~h}$ e $10 \mathrm{~h}$ pósinfecção. $\mathrm{O}$ teste foi realizado em triplicata e foram contadas 100 células por lamínula, os resultados estão expressos como $\pm \mathrm{DP}, \mathrm{n}=3$.

\begin{tabular}{ccccc}
\hline & \multicolumn{3}{c}{ Atividade pós-infecção/horas } & \multicolumn{2}{c}{ Terapêutica } \\
\cline { 2 - 5 } Virucida & $\mathbf{1 0 h}$ & $\mathbf{8 h}$ & $\mathbf{1 0 h}$ \\
$\mathrm{nyLN} \mu \mathbf{h} / \mathbf{m L}$ & $\mathbf{8 h}$ & $44,50 \pm 4,00$ & $66,00 \pm 3,60$ & $56,83 \pm 9,66$ \\
& $47,50^{*} \pm 3,06$ & $23,41 \pm 2,47$ & $30,49 \pm 2,59$ & $28,33 \pm 0,95$ \\
0,5 & $28,66 \pm 0,47$ & $(47 \%)$ & $(54 \%)$ & $(50 \%)$ \\
& $(39,7 \%)^{* *}$ & $22,50 \pm 4,24$ & $27,83 \pm 2,59$ & $25,33 \pm 0,47$ \\
2,5 & $23,83 \pm 1,65(47 \%)$ & $(49,5 \%)$ & $(58 \%)$ & $(55,4 \%)$ \\
\hline
\end{tabular}

$\mathrm{CV}$ : Controle de vírus

* número de focos fluorescentes.

** \% de inibição de focos fluorescentes

DP: Desvio Padrão

\section{Discussão}

Durante as últimas décadas, vários trabalhos demonstraram a atividade antiviral de centenas de extratos vegetais nos quais, a clorofila é testada como parte do extrato bruto ou purificada. Destes, um número significativo mostrou atividade antiviral (GLATTHAAR-SAALMÜLLER; SACHER; ESPERESTER, 2001). Este trabalho avaliou o efeito da CHLN na multiplicação de poliovírus em células HEp-2. Com relação à porcentagem de inibição viral, o tratamento do vírus com a CHLN antes da infecção resultou em inibição que foi maior na concentração de $2,5 \mu \mathrm{g} / \mathrm{mL}$ da droga. O mesmo foi observado no teste terapêutico, no qual a CHLN foi mantida no meio durante todo o experimento. No teste profilático, onde foi avaliada a sua ação protetora contra infecção viral, a CHLN foi pouco efetiva diminuindo o título viral em no máximo $10 \%$ na mais alta concentração testada.

A atividade virucida e o teste terapêutico da CHLN,monitoradospelotestedeimunofluorescência indireta, mostraram que houve uma diminuição percentual de cerca de 40 a 58 no número de células apresentando focos fluorescentes, 8 e $10 \mathrm{~h}$ pós-infecção, nas duas concentrações testadas. Foi demonstrado que a CHLN inibe a fragmentação nuclear, em células HEp-2, induzida por poliovírus (BOTELHO et al., 2004) e, como foi verificado nesta pesquisa, ela também foi mais efetiva nos testes virucida e terapêutico.

A inibição na multiplicação do poliovírus por compostos extraídos de plantas foi demonstrada em alguns trabalhos. Hayashi et al. (1997) mostraram que o 5,6,7-trimetoxiflavona (TMF), extraído de Callicarpajaponica foicapazde inibiramultiplicação de poliovirus em células Vero. Semple et al. (2001) avaliaram a atividade do ácido crisofânico extraído de uma planta medicinal, Dianella longifolia, para o poliovírus. A droga foi capaz de inibir o efeito citopático induzido pelo vírus, quando mantida no meio durante o experimento, mas não apresentou efeito virucida.

As diferenças encontradas na atividade das substâncias quanto ao seu efeito antiviral podem estar associadas tanto as suas características estruturais, o que pode definir seus mecanismos de ação, quanto à multiplicação dos vírus e seu grau de dependência da célula hospedeira. 
Os dados obtidos sugerem que a CHLN pode estar interagindo diretamente na partícula viral ou nos estágios iniciais do ciclo replicativo do poliovírus, entretanto novos experimentos são necessários para elucidar o mecanismo de ação da CHLN.

\section{Referências}

ARIMOTO, S.; KAN-YAMA, K.; RAI, H.; HAYATSU, $H$. Inhibitory effect of hemin, chlorophyllin and related pyrrole pigments on the mutagenicity of benzo $[a]$ pyrene and its metabolites. Mutation Research: Genetic Toxicology, Amsterdam, v. 345, n. 3, p. 127-135, 1995.

BOTELHO, M. V. J.; ORLANDI, J. M.; MELO, F. L.; MANTOVANI, M. S.; LINHARES, R. E. C.; NOZAWA, C. Chlorophyllin protects HEp-2 cells from nuclear fragmentation induced by poliovirus. Letters in Applied Microbiology, London, v. 39, n. 2, p. 174-177, 2004.

BREINHOLD, V.; HENDRICKS, J.; PEREIRA, C.; ARBOGAST, D.; BAILEY, G. Dietary Chlorophyllin is a potent inhibitor of aflatoxin B1 hepatocarcinogenesis in rainbow trout. Cancer Research, Philadelphia, v. 55, n. 1, p. 57-62, 1995.

BRONZETTI, G.; GALLI, A.; DELlA CROCE, C. Antimutagenic effects of chlorophyllin. Basic Life Science, Hong Kong, v. 52, n., p.463-468, 1990.

CRAIG, M. I.; BENENCIA, F.; COULOMBIE, F. C. Antiviral activity of an Acidic polysaccharides fraction extracted from Cedrela tubiflora leaves. Fitoterapia, Milano, v. 72, n. 2, p. 113-119, 2001.

EGNER, P. A.; STANSBURY, K. H.; SNYDER, E. P.; ROGERS, M. E.; HINTZ, P. A.; KENSLER, T. W. Identification and characterization of chlorin e (4) ethyl ester in sera of individuals participating in the chlorophyllin chemoprevention trial. Chemical Research in Toxicology, Washington, v. 13, n. 9, p. 900-906, 2000.

EGNER, P. A.; WANG, J. B.; ZHU, Y. R.; ZHANG, B. C.; WU, Y.; ZHANG, Q. N.; QIAN, G. S.; KUANG, S. Y.; GANGE, S. J.; JACOBSON, L. P.; HELZLSOUER, K. J.; BAILEY, G. S.; GROOPMAN, J. D.; KENSLER, T. W. Chlorophyllin intervention reduces aflatoxinDNA adducts in individuals at high risk for liver cancer. Proceedings of the National Academy of Sciences, Washington, v. 98, n. 25, p. 14601-14606, 2001.

EGNER, P. A.; MUNOZ, A.; KENSLER, T. W. Chemoprevention with chlorophyllin in individuals exposed to dietary aflatoxin. Mutation Research, London, v. 523-524, p. 209-216, 2003.
GLATTHAAR-SAALMÜLLER, B.; SACHER, F.; ESPERESTER, A. Antiviral activity of an extract derived from roots of Eleutherococcus senticosus. Antiviral Research, Amsterdam, v. 50, n. 3, p. 223-228, 2001.

HAYASHI, K.; HAYASHI, T.; OTSUKA, H.; TAKEDA, Y. Antiviral activity of 5,6,7-trimethoxyflavone and its potentiation of the antiherpes activity of acyclovir. Journal Antimicrobiology Chemotherapy, London, v. 39, n., p.821-824, 1997.

JONES, P. S. Strategies for antiviral drug discovery. Antiviral Chemistry and Chemotherapy, London, v. 9, n., p. 283-302, 1998.

KUMAR, S. S.; SHANKAR, B.; SAINIS, K. B. Effect of chlorophyllin against oxidative stress in spleen cells in vitro and in vivo, Biochimica et Biophysica Acta, Germany, v. 1672, n. 2-3, p. 100-111, 2004.

LAGROTA, M. H. C; WIGG, M. D; PEREIRA, L. O. B; FONSECA, M. E. F; PEREIRA, N. A; GUIMARÃES, J. C. Atividade antivirótica do Lapachol. Revista de Microbiologia, São Paulo, v. 14, n. 1, p. 21-26, 1983.

NEGISHI, T.; ARIMOTO, S.; NISHIZAKI, C.; HAYATSU, $H$. Inhibition of the genotoxicity of 3-amino-1-methyl-5H- pyrido[4,3-b]indole (Trp-P-2) in Drosophila by chlorophyll. Basic Life Science, Hong Kong, v. 52, n., p. 341-344, 1990.

NEGISHI, T.; RAI, H.; HAYATSU, H. Antigenotoxic activity of natural chlorophylls. Mutation Research, London, v. 376, n. 1-2, p. 97-100, 1997.

NISHIMURA, T.; TOKU, H.; FUKUYASU, H. Antiviral compounds. XII Antiviral activity of amidinohydrazones of alkoxyphenyl-substituted carbonyl compounds against influenza virus in eggs and in mice. Kitasato Archives Experimental Medicine, Kanagawa, v. 50, n. 1-2, p. 3946, 1977.

ONG, T. M.; WHONG, W. Z.; STEWART, J. D.; BROCKMAN, H. E. Chlorophyllin: a potent antimutagen against environmental and dietary complex mixtures. Mutation Research, London, v. 173, n. 2, p. 111-115, 1986.

REED, L. J.; MÜENCH, H. A simple method of estimating fifty percent end points. American Journal of Epidemiology, Baltimore, v. 27, n. 3, p. 493-497, 1938.

SARKAR, D.; SHARMA, A.; TALUKDER, G. Chlorophyll and chlorophyllin as modifiers of genotoxic effects. Mutation Research, London, v. 318, n. 3, p. 239$247,1994$. 
SHARMA, D.; KUMAR, S. S.; SAINIS, K. B. Antiapoptotic and immunomodulatory effects of chlorophyllin. Molecular Immunology, Elmsford, v. 44, n. 4, p. 347-358, 2007.

SEMPLE, S. J.; PYKEB, S. M.; REYNOLDSC, G. D.; FLOWERD, R. P. In vitro antiviral activity of the anthraquinone chrysophanic acid against poliovirus. Antiviral Research, London, v. 49, n. 3, p. 169-178, 2001.
WARNER, J. R.; NATH, J.; ONG, T. M. Antimutagenicity studies of chlorophyllin using the Salmonella arabinoseresistant assay system. Mutation Research, London, v. 262, n. 1, p. 25-30, 1991.

YUN, C. H.; SON, C. G.; CHUNG, D. K.; HAN, S. H. Chlorophyllin attenuates IFN- $\gamma$ expression in lipopolysaccharide-stimulated murine splenic mononuclear cells via suppressing IL-12 production, International Immunopharmacology, Amsterdam, v. 5, n. 13-14, p. 1926-1935, 2005. 
